\title{
Influence of male density on guarding behaviour in the water strider Aquarius paludum (Heteroptera: Gerridae)
}

\author{
Atsuo MATSUEDA and KenJI FUJISAKI \\ Laboratory of Insect Ecology, Graduate School of Agriculture, Kyoto University, Kitashirakawa Oiwake-cho Sakyo-ku, Kyoto City, \\ Kyoto, 606-8502, Japan; e-mail: ato.mted@gmail.com
}

Key words. Heteroptera, Gerridae, Aquarius paludum, mating behaviour, sex ratio, male density, isolation period, struggle duration, guarding behaviour decision, water strider

\begin{abstract}
In species with last sperm precedence, post-mating guarding behaviour by males is effective for avoiding sperm displacement by additional males. However, for males to guard their mates under all circumstances may be undesirable, particularly when the population density of conspecific rival males is low. To better understand the effects of rival density on mate guarding behaviour, we compared post-copulatory behaviour in males artificially subjected to different male densities using Aquarius paludum. Our results indicate that males of $A$. paludum modulate their post-copulatory behaviour based on previously experienced rival densities.
\end{abstract}

\section{INTRODUCTION}

The males of many insect species use a variety of tactics to ensure the paternity of offspring. In species with last sperm precedence, post-mating guarding behaviour by males is effective to avoid sperm displacement by additional males (Arnqvist, 1988; Mclain, 1989; Harari et al., 2003). Males are aggressive in their guarding behaviours (Arnqvist, 1989; Vepsäläinen \& Savolainen, 1995), and in some species, act to chemically suppress female sexual receptivity via secretions from the accessory gland (Chen et al., 1988). However, contact guarding is costly to both sexes. In males, prolonged guarding behaviour inhibits additional copulation with other females (Yamamura, 1986) and restricts male foraging behaviour (Saeki et al., 2005a). In females, guarding behaviour by males leads to slower movement, greater risk of predation and high energy costs (Arnqvist, 1989; Fairbairn, 1993; Rowe, 1994; Watson et al., 1998). However, resisting the mating attempts of males also increases the predation risk and energy costs for females (Rowe, 1994; Watson et al., 1998).

Situation-dependent behaviour is a strategy for minimizing the costs of guarding behaviour to both sexes. The model proposed by Yamamura (1986) suggests that for males to guard their mates is not necessarily adaptive, particularly when the population density of rivals (i.e., the male ratio) is low. Consistent with this hypothesis, previous studies have demonstrated that mate guarding behaviour is influenced by the sex ratio in several species (Jablonski \& Vepsäläinen, 1995; Muse \& Ono, 1996; Wada et al., 1999; Saeki et al., 2005b). Females, however, may accept guarding if the cost of repelling the mating attempts of males is greater than the cost of accepting them (Wilcox, 1984; Rowe, 1992; Watson et al., 1998).

Water striders are excellent models for examining mate guarding behaviour, as many water strider species exhibit last-male sperm precedence (Arnqvist, 1988). Thus, male water striders that "guard" their mates by remaining mounted after copulation have an improved chance of retaining paternity (Rowe, 1992; Rowe et al., 1994; Amano \& Hayashi, 1998). In addition, the mating behaviour of water striders is easy to observe because it follows a well established sequence, including the male mating attempt, pre-mating struggle, copulation, post-mating struggle and post-mating guarding behaviour (Amano \& Hayashi, 1998).

In this study, we examined how the mate guarding behaviour of males changes with the previously experienced density of conspecific males using the water strider Aquarius paludum (Fabricius). To simulate different densities of males, we isolated group-reared males for several periods before placing them with virgin females. In nature, A. paludum is distributed in various aquatic habitats and may occasionally experience low male ratios and low population densities. Therefore, the frequency of males displaying guarding behaviour is expected to decrease after longer periods of isolation, as predicted by the model of Yamamura (1986). Changes in the postcopulatory guarding behaviour of males may be observed as follows: voluntary dismounting behaviour, suppressing the female post-copulatory struggle and/or dislodging from the female during the post-copulatory struggle. The latter behaviour is reflected by male resistance to female struggling, i.e., may reflect male post-copulatory persistence.

\section{MATERIAL AND METHODS}

\section{Rearing}

In July 2002, adults of $A$. paludum were captured from ponds at the Northern Campus of Kyoto University in Kyoto City, Japan $\left(35^{\circ} 0^{\prime} \mathrm{N}, 135^{\circ} 8^{\prime} \mathrm{E}\right)$. Individuals were reared in the laboratory for several generations under constant light conditions (16L : $\left.8 \mathrm{D}, 25^{\circ} \mathrm{C}\right)$ in small aquaria $(24 \times 34 \times 11 \mathrm{~cm})$ filled approximately $3 \mathrm{~cm}$ deep with water. Nymphs were separated from 
adults and reared. Every 2 days, all water striders were provided with a substantial diet of adult flies (Lucilia illustris Meigen) and water in the aquaria was changed.

All adults were separated by sex within $48 \mathrm{~h}$ of emergence. Males were reared in groups of four or five males per aquarium $(12 \times 20 \times 14 \mathrm{~cm} ; 3 \mathrm{~cm}$ water depth). To allow males to experience high male densities after maturity, group-rearing was continued for approximately 3 weeks. Females were reared in groups of four or five females per aquarium $(12 \times 20 \times 14 \mathrm{~cm}$; 3 cm water depth). Because females of $A$. paludum mature within 1-2 weeks of emergence, all females were reared for approximately 3 weeks prior to the observation period.

Yamamura's (1986) model predicts that males will not guard their mates when females are unlikely to encounter other males before egg-laying. In nature, the mean duration of guarding behaviour (i.e., time between copulation and oviposition) in $A$. paludum is $18.2 \mathrm{~h}$ (Amano \& Hayashi, 1998). Therefore, when males do not encounter other males for more than $18.2 \mathrm{~h}$, they may not exhibit guarding behaviour. However, manipulating the frequency of such encounters is difficult. To simulate various rival densities experienced by $A$. paludum males, individuals were isolated for $0,24,48$ or $72 \mathrm{~h}$ prior to copulation $(n=44$, $42,24,16$, respectively) in containers ( $8 \mathrm{~cm}$ in diameter, $5 \mathrm{~cm}$ in height) filled approximately $1 \mathrm{~cm}$ deep with water. All females were treated equally; they did not experience an isolation period, copulation or mating attempt by males prior to observation in this experiment.

\section{Behavioural observations}

All males were allowed to feed for $6 \mathrm{~h}$ prior to observation to avoid any negative effects of poor nutritional state on mating behaviour. Each male was then placed into an aquarium $(12 \times$ $20 \times 14 \mathrm{~cm} ; 3 \mathrm{~cm}$ water depth) with one virgin female. This female was reared with other virgin females until just prior to the observation period. No food or substrates for resting and oviposition were provided. A video camera was installed $30 \mathrm{~cm}$ above the water surface, and recording continued for $90 \mathrm{~min}$ after water striders were placed in the aquarium. If termination of copulation was delayed, recording was extended for $30 \mathrm{~min}$ to fully observe post-mating behaviour. The termination of copulation was monitored by direct observation at intervals of approximately $15 \mathrm{~min}$ because it could not be clearly determined from video recordings. However, the copulation duration was not recorded because the mean duration of copulation for $A$. paludum was previously reported to be $7.8 \mathrm{~min}$ (Amano \& Hayashi, 1998), meaning that our intervals of direct observation $(15 \mathrm{~min})$ were too long to detect any differences in copulation duration. Furthermore, continual observation throughout the experiment to record the exact duration of copulation may have disrupted the post-mating behaviour of the water striders.

During the behavioural analyses, we recorded the length of time between the introduction and the first mating attempt by males, the duration of the post-mating struggle by females and the type of post-mating behaviour. Post-mating behaviour was classified as follows: female struggled and dislodged the male (type SD); female struggled, but the male remained mounted (type SG); female did not struggle, and the male remained on the female until the end of the observation period (type NS); or copulation continued until the end of the observation period (type CC). Female struggling behaviours included somersaults and attempts to remove the male's forelegs. If the female struggling behaviour did not change, the duration of the struggle in type SD behaviour could be used as an index of male resistance to the female struggle. If the struggle was interrupted for $5 \mathrm{~s}$ or more, the interval was excluded from the duration of the strug- gle. When type SG behaviour was observed, we could not determine whether the female had given up dislodging the male; thus, the duration of struggle was excluded from analysis.

Previous studies have suggested that the frequency of harassment (failed mating attempts) affects the post-copulatory struggle of a female (Rowe, 1992; Weigensberg \& Fairbairn, 1994; Watson et al., 1998). Therefore, to exclude the effect of harassment on female behaviour, trials in which harassment occurred were excluded from the analysis of post-mating behaviour.

\section{Statistical tests}

We excluded type CC behaviour from the analysis and focused only on post-mating behaviour. Logistic regression was used to analyse changes in the frequency of guarding behaviour, the frequency of dislodged males as a result of female struggle and the frequency of female struggle as a function of isolation period. The length of time to the first mating attempt and the duration of the post-mating struggle in females were logarithmically transformed and analysed via linear regression analysis. All analyses were performed using Statview 5.0 (SAS Institute Inc., Cary, NC).

\section{RESULTS}

The duration to the first mating attempt was not influenced by the length of the isolation period experienced by the male prior to copulation $(\ln y=\ln 135.0+0.0037 x, n=$ $100, P=0.68$; Fig. 1). However, previously experienced rival density (i.e., as simulated by pre-copulatory isolation periods) affected post-mating guarding behaviour (Table 1). Although no males dismounted from a female voluntarily (i.e., all guarding behaviours terminated as a result of female struggle), the frequency of males that persisted in post-copulatory guarding behaviour decreased as the isolation period increased (odds ratio [OR] of 0.967 for type SD vs. type SG and NS behaviour; $95 \%$ confidence interval $[\mathrm{CI}],-0.0529$ to $-0.0163 ; P<0.001$; Fig. 2a). When post-mating female struggle was observed, the frequency of dislodged males increased with the isolation period (OR of 1.03 for type SD vs. type SG behaviour; $95 \%$ CI, 0.00213 to $0.0529 ; P<0.05$; Fig. $2 b)$. The dura-

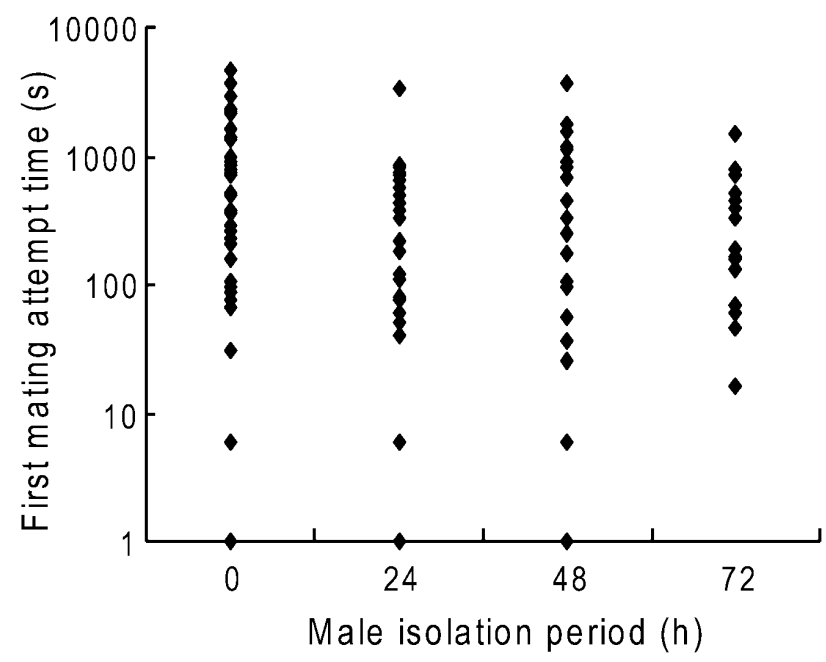

Fig. 1. Relationship between the duration to first mating attempt and the length of the pre-copulatory isolation period in males $(\ln y=\ln 135.0+0.0037 x, n=100, p=0.68)$. 

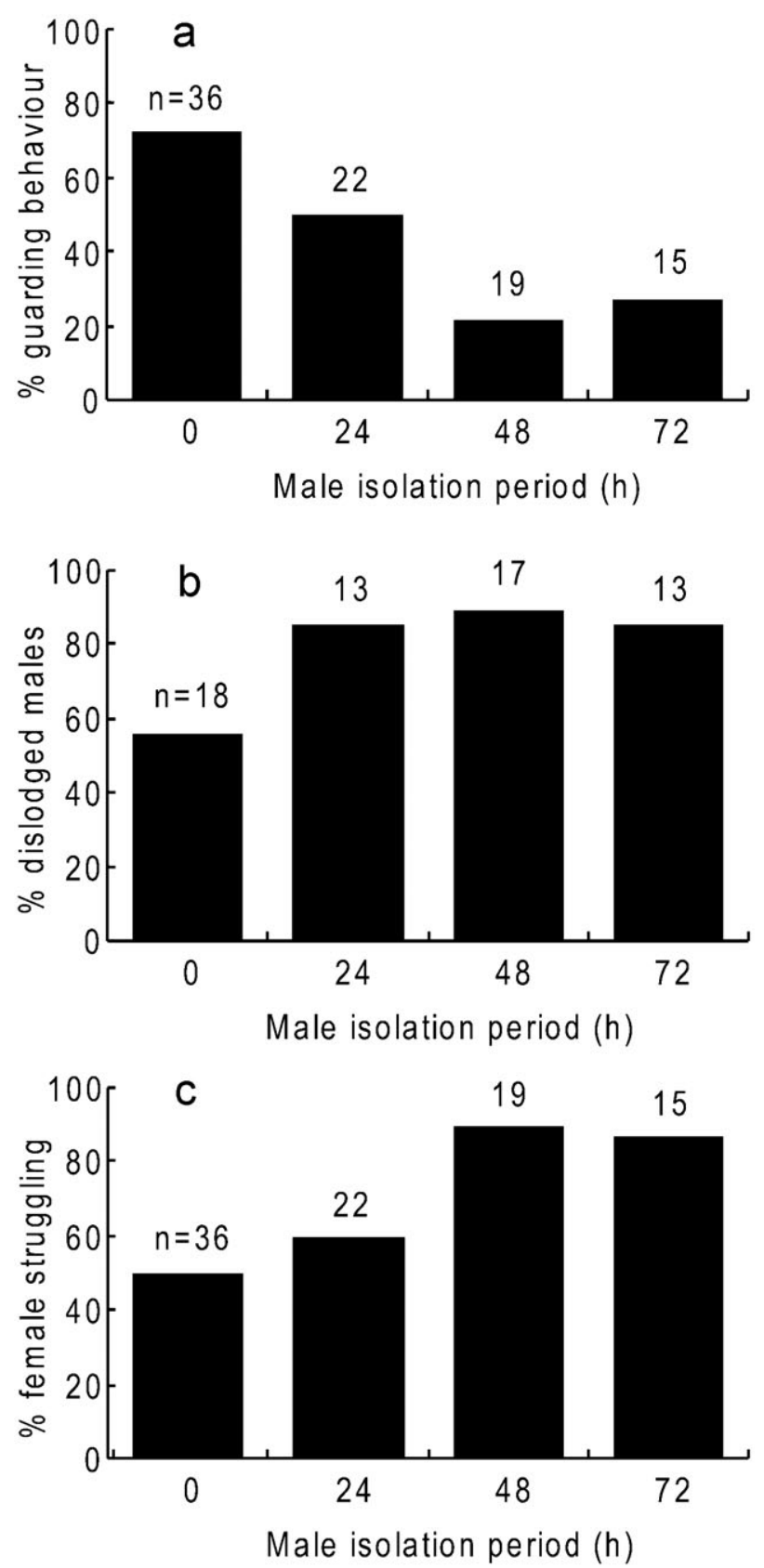

Fig. 2. Association of increasing pre-copulatory isolation period with three post-copulatory behaviours in male and female water striders: $a-$ the frequency of males persisting in post-copulatory guarding behaviour (logistic regression $p<$ $0.001) ; \mathrm{b}$ - the frequency of dislodged males (logistic regression $p<0.05$ ); $\mathrm{c}-$ the frequency of female struggle (logistic regression $p<0.01$ ).

tion of the male isolation period significantly affected female behaviour (type SD and SG vs. type NS behaviour). The frequency of the post-mating struggle increased with isolation period (OR, 1.03; 95\% CI, -0.0532 to $-0.0127 ; P<0.01$; Fig. 2 c). When males were dislodged, the duration of the struggle decreased significantly with the isolation period $(\ln y=\ln 75.8-0.0185 x, n$ $=47, P<0.05$; Fig. 3).
TABLE 1. The frequency and percentage of the four types of post-copulation behaviour.

\begin{tabular}{cccccc}
\hline \multirow{2}{*}{$\begin{array}{l}\text { Isolated } \\
\text { period (h) }\end{array}$} & \multicolumn{5}{c}{ Frequency of behavior (\%) } \\
\cline { 2 - 5 } & Type SD & Type SG & Type NS & Type CC & \\
\hline 0 & $10(25.6)$ & $8(20.5)$ & $18(46.2)$ & $3(7.7)$ & 39 \\
24 & $11(40.7)$ & $2(7.4)$ & $9(33.3)$ & $5(18.5)$ & 27 \\
48 & $15(78.9)$ & $2(10.5)$ & $2(10.5)$ & $0(0.0)$ & 19 \\
72 & $11(73.3)$ & $2(13.3)$ & $2(13.3)$ & $0(0.0)$ & 15 \\
\hline
\end{tabular}

Post-mating behaviour was classified as follows: female struggled and dislodged the male (type SD); female struggled, but the male remained on the female (type SG); female did not struggle, and the male remained on the female until the end of the observation period (type NS); or copulation continued until the end of the observation period (type CC).

\section{DISCUSSION}

The length of the isolation period had no influence on the duration to first mating attempt (Fig. 1). However, the male's motivation to continue mating behaviour may be affected not only by rival density, but also by the period of separation from females. In this experiment, males and females were separated for 3 weeks, after which they were brought together during the observation period. This period of separation may have affected male motivation to mate to a greater degree than previously experienced male density, for which reason we observed no difference in the duration to first mating attempt according to rival density.

Our results are consistent with theoretical prediction of Yamamura (1986). In this experiment, the frequency of males exhibiting guarding behaviour decreased as a result of previously experienced low rival density (i.e., increased isolation period prior to copulation; Fig. 2a).

Apparently, the guarding behaviour of the water strider is decided through three stages. First, whether males voluntarily dismount from their mates after copulation. In this first stage, the change in a male's behaviour can be directly observed. Second, whether females struggle to

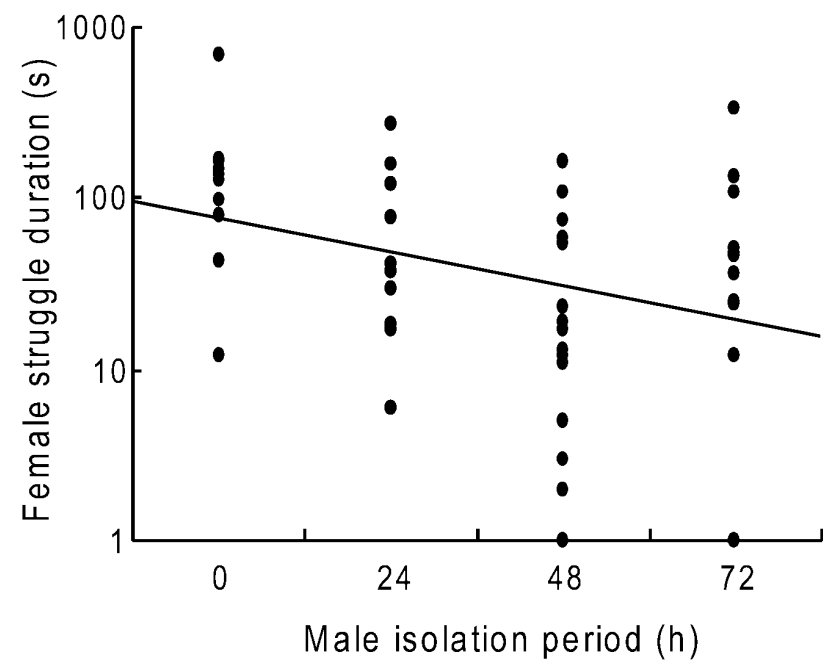

Fig. 3. Correlation between male pre-copulatory isolation period and the duration of female struggle. Only type SD behaviour is shown $(\ln y=\ln 75.8-0.0185 x, n=47, p<0.05)$. 
dislodge males when they do not voluntarily dismount. In this stage, the change in the male's behaviour can be observed via the change in a female's behaviour that would be controlled by males. Third, whether males can resist the female's struggle. In this third stage, a change in the male's guarding behaviour decision can be observed because a change in the behaviour of both sexes might be due to the differences in the isolation periods experienced by the males in this experiment.

In the first stage, no males voluntarily dismounted after copulation, and no change in male behaviour was observed. This is in contrast to the response of Gerris lacustris, a closely related species whose males dismount from females after copulation (Vepsäläinen \& Savolainen, 1995). However, in other water strider species, males are not reported to voluntarily dismount, and females are known to terminate the guarding behaviour (Rowe, 1992). However, the reason why males do not dismount has not been examined, and further studies are required to clarify the factors underlying the differences in mating behaviour between these two closely related species.

In the second stage, the post-copulatory struggle frequency of females of $A$. paludum significantly increased with the pre-copulatory isolation period of males, which suggests that males of $A$. paludum suppress female resistance. No females in this experiment had previously experienced a male mating attempt, which would influence the post-mating behaviour of the female (Watson et al., 1998). Females are predicted to not accept guarding behaviour when the cost of repelling male mating attempts is lower than that of accepting guarding behaviour (Rowe, 1992; Watson et al., 1998). Therefore, the frequency of female struggle may have been high to avoid the cost of guarding behaviour in all treatments. However, the frequency of female struggle was influenced by the males' experience. Therefore, the observed increase in female struggle was not the result of the experience of the females, but rather that of the males that had been isolated for a greater length of time (Fig. 2c).

In the third stage (when females struggled against males), two major changes in post-mating behaviour occurred with increasing pre-copulatory isolation as follows: the frequency of dislodged males increased, and the duration of female struggle necessary to dislodge a male decreased (Figs 2b, 3). These results may have been due to the resistance of the males to the females' struggle as well as to the intensity of the struggle. However, the former could not be determined because the latter was not measured in this experiment. Additionally, both the frequency of the females' struggle as well as the intensity of the struggle was likely influenced by the males. Therefore, we suggest that the change in the frequency of dislodged males and the duration of the females' struggle is a response to the males' guarding behaviour decisions; however, further studies are required to examine the change in the males' resistance to the females' struggle.

Why males of $A$. paludum suppress female resistance is unclear. In some water strider species, female struggle has a large influence on the guarding behaviour of males (Rowe, 1992; Weigensberg \& Fairbairn, 1994; Ronkainen et al., 2005). In the present study, $56 \%$ of females that struggled were able to dislodge males that had not been isolated, i.e., males that should exhibit the most intense guarding behaviour. Therefore, the ability to suppress female struggle would be of great reproductive benefit to males that should guard, and a similar capability in controlling female behaviour has been demonstrated previously in other species. For example, in Drosophila melanogaster (Chen et al., 1988) and Togo hemipterus (Scott) (Himuro \& Fujisaki, 2008), males chemically control female sexual receptivity via secretions from the accessory gland. Physical mechanisms of suppression may include constriction of the female thorax or the generation of a vibration signal as in Aquarius elongatus (Uhler) (Hayashi, 1985). At present, no chemical and/or physical mechanism to suppress female struggle in A. paludum is known. The copulation duration may indicate how males suppress female resistance, although it was not determined in this experiment. Therefore, copulation duration should be measured in further studies.

Our results suggest that the males of $A$. paludum alter their guarding behaviour based on previous experiences of rival density, and that males suppress the postcopulatory struggle of females. The observed changes in the frequency of dislodged males and struggle duration, however, are insufficient to determine the extent of male resistance to female struggle. Because our experiment could not exclude the effect of female struggle on the frequency of dislodged males or struggle duration, further studies are required to confirm whether the changes observed here represent a true change in male resistance to female struggle.

ACKNOWLEDGEMENTS. We thank P. Goodwyn, Y. Nakajima, S. Noriyuki, S. Oku and K. Ohtsuka for their helpful advice concerning this manuscript.

\section{REFERENCES}

Amano H. \& Hayashi K. 1998: Costs and benefits for water strider (Aquarius paludum) females of carrying guarding, reproductive males. Ecol. Res. 13: 263-272.

ARNQVisT G. 1988: Mate guarding and sperm displacement in the water strider Gerris lateralis Schumm. (Heteroptera: Gerridae). Freshw. Biol. 19: 269-274.

ARnQvist G. 1989: Multiple mating in a water strider: mutual benefits or intersexual conflict? Anim. Behav. 38: 749-756.

Chen P.S., Stumm-Zollinger E., Aigaki T., Balmer J., Blenz M. \& Bohien P. 1988: A male accessory gland peptide that regulates reproductive behavior of female D. melanogaster. Cell 54: 291-298.

FAIRBAIRN D.J. 1993: Costs of loading associated with matecarrying in the waterstrider, Aquarius remigis. Behav. Ecol. 4: 224-231.

Harari A.R., Landolt P.J., O'Brien C.W. \& Brockmann H.J. 2003: Prolonged mate guarding and sperm competition in the weevil Diaprepes abbreviatus (L.). Behav. Ecol. 14: 89-96.

HAYASHI K. 1985: Alternative mating strategies in the water strider Gerris elongatus (Heteroptera, Gerridae). Behav. Ecol. Sociobiol. 16: 301-306. 
Himuro C. \& Fujisaki K. 2008: Males of the seed bug Togo hemipterus (Heteroptera: Lygaeidae) use accessory gland substances to inhibit remating by females. J. Insect Physiol. 54: $1538-1542$.

JABLONSKI P. \& VePSÄLÄINEN K. 1995: Conflict between sexes in the water strider Gerris lacustris: A test of two hypotheses for male guarding behavior. Behav. Ecol. 6: 388-392.

MCLAIN D.K. 1989: Prolonged copulation as a post-insemination guarding tactic in a natural population of the ragwort seed bug. Anim. Behav. 38: 659-664.

Muse W.A. \& ONO T. 1996: Copulatory behavior and postcopulatory mate guarding in a grasshopper Atractomorpha lata Motschulsky (Orthoptera: Tetrigidae) under laboratory conditions. Appl. Entomol. Zool. 31: 233-241.

Ronkainen K., Kaitala A. \& Huttunen R. 2005: The effect of abdominal spines on female mating frequency and fecundity in a water strider. J. Insect Behav. 18: 619-631.

Rowe L. 1992: Convenience polyandry in a water strider: foraging conflicts and female control of copulation frequency and guarding duration. Anim. Behav. 44: 189-202.

Rowe L. 1994: The costs of mating and mate choice in water striders. Anim. Behav. 48: 1049-1056.

Rowe L., Arnqvist G., Sin A. \& Krupa J.J. 1994: Sexual conflict and the evolutionary ecology of mating patterns - water striders as a model system. Trends Ecol. Evol. 9: 289-293.
Saeki Y., Kruse K.C. \& Switzer P.V. 2005a: Physiological costs of mate guarding in the japanese beetle (Popillia japonica Newman). Ethology 111: 863-877.

Saeki Y., Kruse K.C. \& Switzer P.V. 2005b: The social environment affects mate guarding behavior in Japanese beetles, Popillia japonica. J. Insect Sci. 5: 18-23.

VEPSÄLÄINEN K. \& SAVOLAINEN R. 1995: Operational sex ratios and mating conflict between the sexes in the water strider Gerris lacustris. Am. Nat. 146: 869-880.

Wada S., Tanaka K. \& Goshima S. 1999: Precopulatory mate guarding in the hermit crab Pagurus middendorfii (Brandt) (Decapoda: Paguridae): effects of population parameters on male guarding duration. J. Exp. Mar. Biol. Ecol. 239: 289-298.

Watson P.J., Arnqvist G. \& Stallmann R.R. 1998: Sexual conflict and the energetic costs of mating and mate choice in water striders. Am. Nat. 151: 46-58.

Weigensberg I. \& Fairbairn D.J. 1994: Conflicts of interest between the sexes: a study of mating interactions in a semiaquatic bug. Anim. Behav. 48: 893-901.

WILCOX R.S. 1984: Male copulatory guarding enhances female foraging in a water strider. Behav. Ecol. Sociobiol. 15: $171-174$.

YAMAMURA N. 1986: An evolutionarily stable strategy (ESS) model of postcopulatory guarding in insects. Theor. Popul. Biol. 29: 438-455.

Received July 13, 2010; revised and accepted May 3, 2011 